\title{
CONGENITAL DYSERYTHROPOIETIC ANEMIA: AN ETIOPATHOLOGICAL STUDY
}

Vinod Kumar Ravilala1, Narahari Bapanpally², Radhika Krishna Othuluru³, Geetha Kayla ${ }^{4}$ Bheemavathi Anugu ${ }^{5}$, Ramani Malleboyina ${ }^{6}$

${ }^{1}$ Assistant Professor, Department of Paediatrics, Niloufer Hospital.

${ }^{2}$ Assistant Professor, Department of Paediatrics, Niloufer Hospital.

${ }^{3}$ Assistant Professor, Department of Pathology, Niloufer Hospital.

${ }^{4}$ Assistant Professor, Department of Pathology, Niloufer Hospital.

5 Senior Resident, Department of Pathology, Niloufer Hospital.

${ }^{6}$ Professor, Department of Pathology, Niloufer Hospital.

\section{ABSTRACT}

AIMS

To evaluate the role of blood and bone marrow findings in the diagnosis of congenital dyserythropoietic anaemias type I and type II.

\section{SETTINGS AND DESIGN}

Dyserythropoietic anaemia is suspected when there is a suboptimal reticulocyte response for the degree of anaemia. Congenital dyserythropoetic anaemias are a group of rare hereditary disorders of hematopoiesis. It is believed that CDA is often under diagnosed. Knowledge of CDA workup in a patient of haemolytic anaemia is often rewarding.

\section{MATERIALS AND METHODS}

All the cases diagnosed as CDA at a tertiary paediatric centre were reviewed with respect to clinical and serological data, peripheral smear and bone marrow study findings. The haematological changes in CDA were analyzed with respect to the diagnosis.

\section{RESULTS AND CONCLUSION}

The light microscopic findings of the peripheral smear and bone marrow aspirate were found to be highly specific for the diagnosis of CDA. Significant differences were also noted between type I and type II CDA.

\section{KEYWORDS}

Congenital Dyserythropoietic Anemia, Bone Marrow.

HOW TO CITE THIS ARTICLE: Ravilala VK, Bapanpally N, Othuluru RK, et al. "Congenital dyserythropoietic anemia: An etiopathological study." Journal of Evolution of Medical and Dental Sciences 2015; Vol. 4, Issue 105, December 31;

Page: 17027-17030, DOI: 10.14260/jemds/2015/2576

\section{INTRODUCTION}

Congenital dyserythropoietic anemias comprise a group of very rare hereditary disorders characterized by ineffective erythropoiesis and distinct morphological abnormalities of erythroblasts in the bone marrow. The classification proposed in 1968 is still used today.(1,2) Very few cases have been diagnosed worldwide.(3)

They are familial disorders characterized by association of refractory anemia and ineffective erythropoiesis with multinuclearity and karyorrhexis.(3) Three types of CDA designated type I, II and III have been identified on the basis of morphologic and serological characteristics. Morphologic hallmarks of erythroblasts are per se specific, but may also be observed as single abnormalities in other disorders of erythropoiesis. As the clinical and laboratory findings are not distinctive, it is believed that CDA is often underdiagnosed. We attempted to evaluate the characteristic morphological abnormalities in patients with CDA I and CDA II.

\section{MATERIALS AND METHODS}

Study was carried at a tertiary paediatric referral center over a period of five years (2010-2015).

Financial or Other, Competing Interest: None.

Submission 24-11-2015, Peer Review 25-11-2015,

Acceptance 26-12-2015, Published 30-12-2015.

Corresponding Author:

Dr. Vinod Kumar Ravilala,

Assistant Professor of Paediatrics,

Niloufer Hospital for Women and Children.

E-mail:vkravilala@gmail.com

DOI:10.14260/jemds/2015/2576
All the case records of patients diagnosed with CDA were reviewed to determine clinical and hematological parameters. All the causes of hemolytic anemia were ruled out before bone marrow examination. The common causes of hemolytic anemia like Thalassemia, hereditary spherocytosis were ruled out. Serum B12 and folate levels were estimated to rule out megaloblastic anemia. In all the cases diagnosed as CDA by bone marrow aspiration and acidified serum lysis test (Ham's test). Erythrocyte agglutination and lysis was not performed due to non-availability of reagent. All the clinical details including age, hemolytic facies and presence of icterus, hepatosplenomegaly and transfusion history were documented. Investigative profile was noted down in all the cases. The bone marrow aspiration slides were reviewed with respect to all the expected morphological findings of CDA and tabulated.

\section{RESULTS}

A total of 7 cases of CDA were identified in the period of five years from 2010 to 2015. The clinical features and investigations are illustrated (Image 1, tables I \& II). Based on investigations 5 patients were categorized as CDA type II and 2 patients as CDA type I. In type 1 presentation was later than type 2. History of consanguinity was present in five cases. History of similar complaints in the family members could not be elicited.

All the patients had pallor and hepatosplenomegaly, total and differential WBC counts and platelet counts were near normal in all the cases. Peripheral smear examination revealed varying degrees of poikilocytosis, hypochromia and tear drop cells and erythroblastosis. All types of poikilocytes were noted. Macrocytes were seen in CDA type 1. 
Marrow hypercellularity and distinct erythropoietic hyperplasia was present in all the cases. The presence and frequency of pertinent abnormalities in erythroblasts in CDA type I and II (Table 3). Highly significant differences were found for binucleated cells (Image 2), abnormalities of chromatin structures, chromatin bridges between the erythroblasts, incompletely divided polypoid cells and karyorrhexis in erythroblasts (Image 3). Bone marrow findings were confirmed by HAMs test.

\begin{tabular}{|c|c|c|c|c|c|c|c|c|c|}
\hline $\begin{array}{l}\dot{z} \\
\dot{\omega}\end{array}$ & $\sum_{m}^{\mathbb{S}}$ & 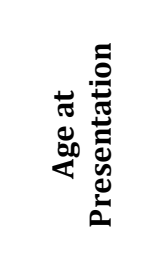 & 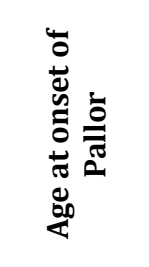 & ڤ્ & 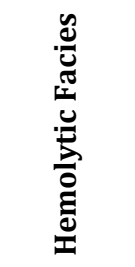 & 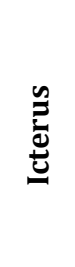 & 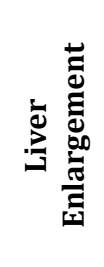 & 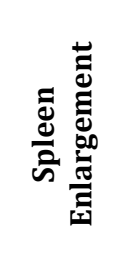 & 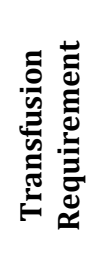 \\
\hline 1 & $85 / 11$ & 5Yeras & 3 Years & $\mathrm{F}$ & Present & Yes & $4 \mathrm{~cm}$ & $3 \mathrm{~cm}$ & yes \\
\hline 2 & $161 / 11$ & 6 Months & Birth & $\mathrm{M}$ & Present & No & $4.5 \mathrm{~cm}$ & $4.5 \mathrm{cms}$ & Yes \\
\hline 3 & $175 / 11$ & $21 / 2$ Years & 2 Years & $\mathrm{F}$ & Absent & No & Nil & Nil & Yes \\
\hline 4 & $90 / 12$ & 4 Months & 4 Months & $\mathrm{F}$ & Present & Yes & $3 \mathrm{cms}$ & $1 \mathrm{cms}$ & once \\
\hline 5 & $34 / 13$ & 4 Years & 3 Years & M & Present & No & + & + & Yes \\
\hline 6 & $49 / 13$ & 18 Months & 8 Months & $\mathrm{M}$ & Present & Yes & $3 \mathrm{cms}$ & + & Yes \\
\hline 7 & $66 / 13$ & $11 / 2$ Years & 1 Years & $\mathrm{F}$ & Absent & No & $2 \mathrm{cms}$ & Nil & Yes \\
\hline
\end{tabular}

\begin{tabular}{|c|c|c|c|c|c|c|c|}
\hline $\begin{array}{c}\text { Sl. } \\
\text { No. }\end{array}$ & $\begin{array}{c}\text { Hemoglobin } \\
\text { (gms/dl) }\end{array}$ & $\begin{array}{c}\text { Reticulocyte } \\
\text { count }\end{array}$ & $\begin{array}{c}\text { Serum } \\
\text { Bilirubin } \\
\text { Total/direct } \\
\text { (mg/dl) }\end{array}$ & $\begin{array}{c}\text { Nucleated } \\
\text { RBCs /100 } \\
\text { WBCs }\end{array}$ & $\begin{array}{c}\text { Serum } \\
\text { ferritin } \\
\text { (ng/ml) }\end{array}$ & $\begin{array}{c}\text { HAM's } \\
\text { test }\end{array}$ & $\begin{array}{c}\text { Type of } \\
\text { CDA }\end{array}$ \\
\hline 1 & 5.1 & $1 \%$ & $3.6 / 6.8$ & $6-9$ & 4861 & Positive & Type II \\
\hline 2 & 10.4 & $1.5 \%$ & - & $1-3$ & - & Negative & Type I \\
\hline 3 & 9.2 & $1 \%$ & $0.3 / 0.2$ & $12-15$ & 325 & Positive & Type II \\
\hline 4 & 7.8 & $1.5 \%$ & - & $10-12$ & - & Positive & Type II \\
\hline 5 & 5 & $2 \%$ & - & $8-10$ & - & Positive & Type II \\
\hline 6 & 8.6 & $1 \%$ & $2.8 / 0.8$ & $3-6$ & - & Negative & Type I \\
\hline 7 & 6.8 & $2 \%$ & - & $18-20$ & 3405 & Positive & Type II \\
\hline
\end{tabular}

\begin{tabular}{|c|c|c|c|c|c|c|c|c|c|c|c|c|}
\hline $\begin{array}{r}\text { Sl. } \\
\text { No. }\end{array}$ & $\begin{array}{l}\text { Age } \\
\text { yrs. }\end{array}$ & E:M & & $\begin{array}{r}N \\
\text { Abno }\end{array}$ & $\begin{array}{l}\text { cleat } \\
\text { mali }\end{array}$ & & $\begin{array}{r}\mathrm{Cl} \\
\mathrm{Abn}\end{array}$ & $\begin{array}{l}\text { matin } \\
\text { nalities }\end{array}$ & Ery & bblas & Mor & hology \\
\hline & & & $\bar{z}$ & 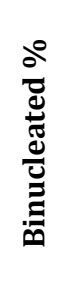 & 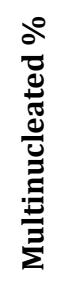 & 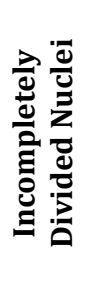 & 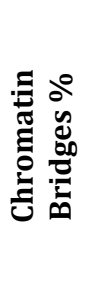 & 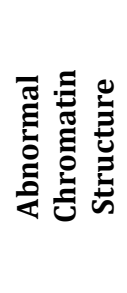 & 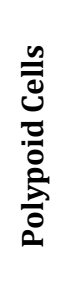 & 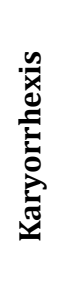 & 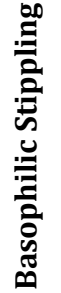 & 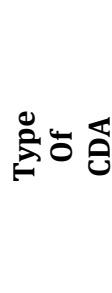 \\
\hline 1 & $5 \mathrm{yrs}$ & $8: 1$ & 20 & 18 & 1.5 & 1 & - & 1 & Nil & 2 & 3 & $\begin{array}{c}\text { CDA } \\
\text { Type II }\end{array}$ \\
\hline 2 & $6 \mathrm{mon}$ & $5: 1$ & 28 & 22 & 0.5 & 3 & 4 & 12 & 4 & 3 & 5 & $\begin{array}{c}\text { CDA } \\
\text { Type I }\end{array}$ \\
\hline 3 & $2 \frac{1}{2} 2 y$ & $2: 1$ & 18 & 10 & 1.5 & 2 & - & - & Nil & 2.5 & 2 & $\begin{array}{c}\text { CDA } \\
\text { Type II }\end{array}$ \\
\hline 4 & $4 \mathrm{mon}$ & $4: 1$ & 22 & 14 & 2.0 & 1 & - & - & Nil & 2 & 2 & $\begin{array}{c}\text { CDA } \\
\text { Type II }\end{array}$ \\
\hline 5 & $4 \mathrm{yrs}$ & $3: 1$ & 20 & 18 & 3.0 & 1 & - & - & Nil & 2.5 & 2 & $\begin{array}{c}\text { CDA } \\
\text { Type II }\end{array}$ \\
\hline 6 & $11 / 2 y$ & $6: 1$ & 25 & 16 & 1.0 & 2 & 5 & 10 & 3 & 4 & 6 & $\begin{array}{c}\text { CDA } \\
\text { Type I }\end{array}$ \\
\hline 7 & $1 \frac{1 / 2 y}{}$ & $4: 1$ & 20 & 12 & 2.0 & 1 & - & - & Nil & 2 & 2 & $\begin{array}{c}\text { CDA } \\
\text { Type II }\end{array}$ \\
\hline
\end{tabular}




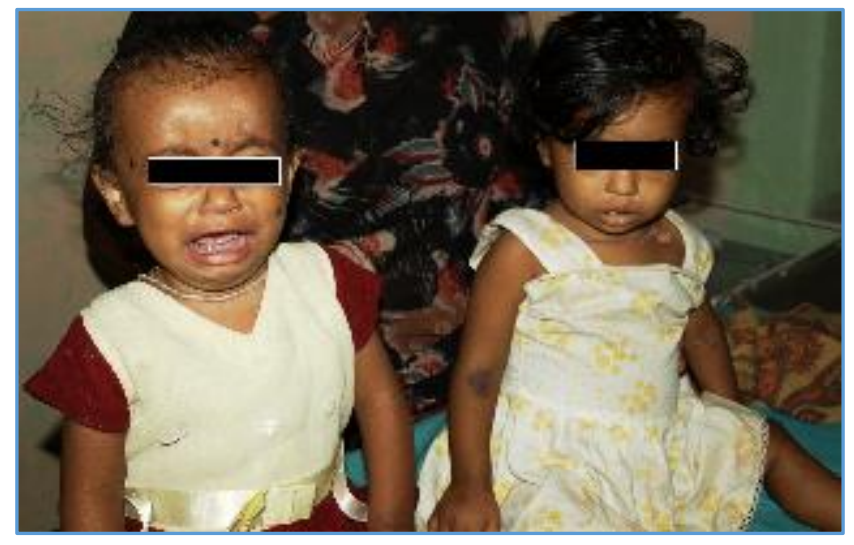

Image 1: Siblings both presenting clinically as CDA type II on bone marrow aspiration

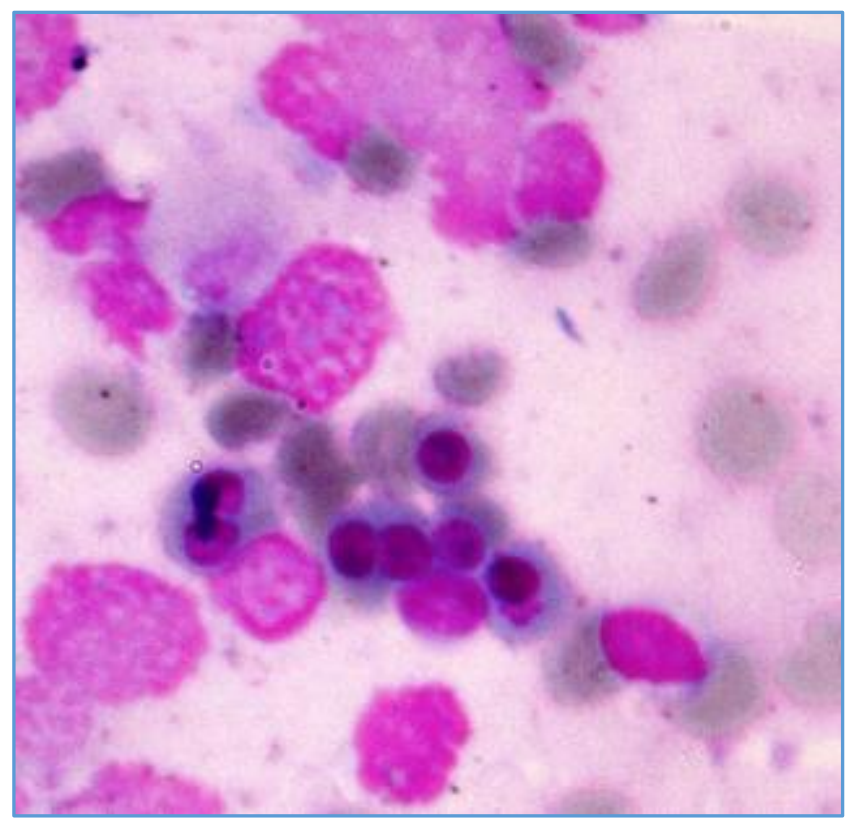

Image 2: Photomicrograph of BMA of CDA Type 1 showing Binucleate Erythroblasts

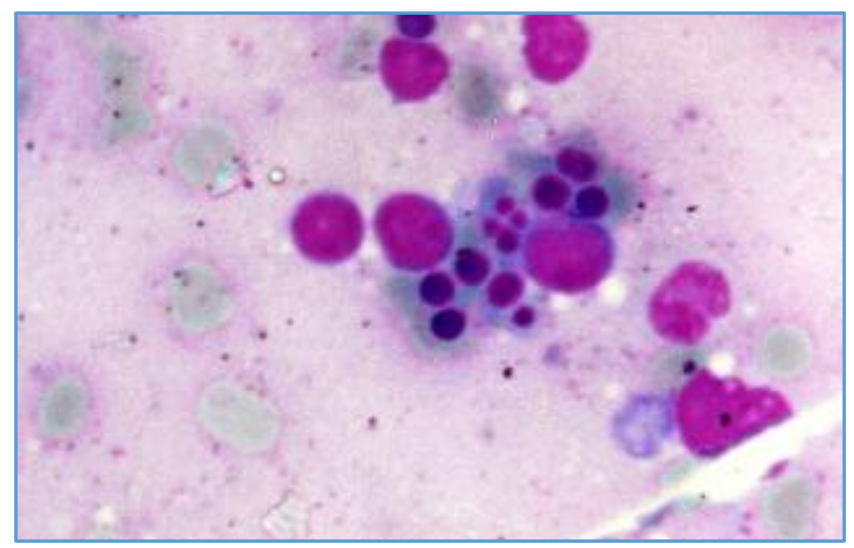

Image 3: Photomicrograph of Bone marrow aspiration of CDA type II showing Karyorrhexis in Erythroblasts

\section{DISCUSSION}

The diagnosis of CDA is primarily based on the morphology of peripheral blood and bone marrow, though the confirmation needs to be done by more refined and costly tests. These tests are expensive and available only in specialized laboratories.

The diagnosis is often delayed. Of the three types, CDA type II is the commonest identified by positive Ham's test and multinucleated erythroblasts. CDA type I is characterized by binuclearity and inter-nuclear chromatin bridging of erythroblasts. CDA type III is the rarest, and is identified by giant erythroblasts with up to 12 nuclei-the gigantoblasts.(1) Few rarer type of CDA have also been identified, which do not fit into the common three types.(1) The pathogenesis of CDA is more clearly known for type II than for others.

There is a defect in the enzymatic glycosylation of membrane proteins. Band 3 glycoprotein, which plays an important role in the organization of cytoskeleton, is abnormal. This in part accounts for the disrupted membrane structure of erythroblasts; a feature characteristic of the disease. $(1,4)$ The end result is an increased rate of phagocytosis of abnormal erythroblasts by bone marrow macrophages. The diagnosis of CDA is often made during childhood, though there is no age limit. It can have an intra-uterine onset with severe anemia, resulting in cardiac failure or the disease may remain undiscovered until late adult life. $(5,6)$

We find in this study that the diagnosis of CDA can be made with high specificity in a well aspirated and prepared bone marrow without need for costly ancillary tests.

Of the three types of CDA, type II is the commonest as noted at our center where 5 out of 7 cases were CDA type II. CDA type I is characterized by binuclearity and internuclear chromatin bridging of erythroblasts. CDA type III is rarest and identified by giant erythroblasts and gigantoblasts with 12 nuclei.(4) Rare types of CDA are also known.

Pathogenesis of CDA is more clearly known for type II than others. There is a defect in the enzyme glycosylation of membrane proteins. Band 3 glycoprotein which plays an important role in the organization of cytoskeleton is abnormal. This in part accounts for disrupted membrane of erythroblasts. $(4,5)$ The end result is increased rate of phagocytosis of abnormal erythroblasts by bone marrow macrophages.

CDA I and CDA II are autosomal recessive disorders and the family members of affected children should be screened. The principal clinical manifestations include hepatosplenomegaly, variable degree of jaundice and hemolytic facies. These features are common to a number of hemolytic and dyserythropoietic anemias. A diagnosis of CDA is considered only after exclusion of these.(3) There are reports of dysmorphic features, patches of brown skin pigmentation, syndactyly and abnormality of nails and ribs in patients with CDA type I.(7). However none of our patients had these somatic malformations.

The smear reticulocyte count was suboptimal for the degree of anemia. Such reticulocyte count response for the degree of anemia in the face of erythroid hyperplasia in the marrow warrants a diagnosis of dyserythropoiesis. All the cases of CDA type II were positive for HEMPAS test. To obtain a statistically reliable result, Boogaert et al.(8) have recommended that the patient's red cells must be reacted against 30 normal sera. The number of sera used in the index study was four. Reclassification of patients to CDA type II is known, due to insufficient number of sera being used in the initial Ham's test.(9)

The diagnosis of CDA can be made with high specificity from morphological analysis alone by light microscopy as the findings such as erythroblast nuclei abnormal. In the first report of patients with CDA from India, Pati et al. described six patients with CDA type II.(10) Prasher et al.(11) have reported a 30-year-old female with CDA type II, who had onset of symptoms at nine years of age. To the best of our knowledge, CDA type I has not been reported from India so far chromatin structure and chromatin bridges are specifically present in good percentage (table3). In CDA type II the most specific finding is presence of binucleated cells. If the fraction of such binucleated cells is significant along with karyorrhexis a 
diagnosis of CDA type 2 can be made even when gene diagnosis is not available.

We conclude that the diagnosis of CDA type I and II can be reliably made from proper examination of carefully prepared bone marrow and peripheral smear.

\section{CONCLUSION}

The considerable time gap between the onset of symptoms and the referral to tertiary center indicates that the disease is seldom suspected. CDA needs to be always considered in the differential diagnosis of difficult anemias, establishing an early diagnosis helps in enhancing quality of life. Results of our study demonstrate that diagnosis of CDA can be made on the basis of hematological findings, particularly in centres where genetic studies are not available.

\section{REFERENCES}

1. Heimpel H, Wendt F, et al. Congenital dyserythropoietic anemia with karyorrhexis and multinuclearity of erythroblasts. Helv MedActa. 1968;34(2):103-15.

2. Wickramasinghe SN. Congenital dyserythropoietic anemias clinical features, haematological morphology and new biochemical data. Blood Rev. 1998;12(3):178-200.

3. Marks PW, Mitus AJ. Congenital dyserythropoietic anemias. Am J Hematol. 1996;51:55-63.

4. Fukuda MN, Klier G, Yu J, et al. Anomalous clustering of underglycosylated band 3 in erythrocytes and their precursor cells in congenital dyserythropoietic anemia type II. Blood. 1986;68:521-529.
5. Kato K, Sugitani M, Kawataki M. Congenital dyserythropoietic anemia type I with fetal onset of severe anemia. J Pediatr Hematol Oncol. 2001;23:63-66.

6. Parez N, Dommergues M, Zupan V. Severe congenital dyserythropoietic anemia type I, prenatal management, transfusion support and alpha-interferon therapy. Br J Hematol. 2000;110:420-423.

7. Brichard B, Vermylen C, Scheiff JM, Michauz JL, Ninane J, Cornu G. Two cases of congenital dyserythropoietic anemia type I associated with unusual skeletal abnormalities of the limbs. Br J Haematol. 1994;86:201202.

8. Boogaet MA, Verwilghen RL. Variants of congenital dyserythropoietic anemia: an update. Haematologia. 1982;15:211-219.

9. Seip M, Skrede S, Bjerve KS, et al. Congenital dyserythropoietic anemia with features of both type I and type II. Scand J Haematol. 1975;15:272-286.10.

10. Pati H, Arya LS, Puri S, et al. Congenital dyserythropoietic anemia, type II (HEMPA). Indian Pediatr. 1986;23:386389.

11. Prasher N, Praser BS. A Congenital dyserythropoietic anemia. J Assoc Physic India. 1989;37:467-468. 